\title{
Erratum to: Physical Exercise Is Safe for Fontan Patients in Hypoxia
}

Härtel J. A. ${ }^{1}$ Müller N. ${ }^{1}$ Manunzio U. ${ }^{1,2}$ Manunzio C. ${ }^{1,2}$ De Marées M. ${ }^{3}$ Wolber M. $^{1}$ Leibold D. $^{1}$ Jung T. ${ }^{1}$ Breuer J. ${ }^{1}$ Herberg U. ${ }^{1}$

\footnotetext{
${ }^{1}$ Department of Pediatric Cardiology, Children's Hospital, University of Bonn, Bonn, Germany

2 Institute of Cardiovascular Research and Sport Medicine, German

Sport University Cologne, Cologne, Germany

3 Institute of Training Science and Sport Informatics, German Sport

University Cologne, Cologne, Germany
}

Thorac Cardiovasc Surg were incorrect in the above-mentioned abstract, published in the abstracts supplement of the journal Thoracic and Cardiovascular Surgeon, volume 67(S 02) on page S101. DOI of the original article is DOI: 10.1055/s-0038-1676629. The name should be listed as "J.A. Härtel" in place of "A.J. Härtel." 